\title{
Evli Çiftlerin Kişilik Profillerinin Karşılaştırılması-II: HEXACO Kişilik Modeli
}

\author{
Arkun TATAR ${ }^{1}$, Gaye SALTUKOĞLU1 ${ }^{1}$, Hüdanur ÖZDEMİR ${ }^{2}$
}

\begin{abstract}
Özet: Bu çalışmada kişilik özelliklerinin, fikir birliği çerçevesinde evlilik uyumuyla ilişkilerinin incelenmesi düşünülmüştür. Bu doğrultuda çalışmada, a) HEXACO Kişilik Envanteri'nin gözlemci formunun kullanılması ve test edilmesi, b) evlilik uyumu açısından HEXACO kişilik modelinin incelenmesi, c) evlilik uyumunda eşler arası fikir birliğinin rolünün incelenmesi amaçlanmıştır. Çalışmaya bir yıl ve daha uzun süre ile evli olan 296 kadın, 253 erkek olmak üzere 549 kişi ile bunların eşleri olmak üzere toplam 1098 kişi katılmıştır. Çiftlerden biri, Çift Uyum Ölçeği'nin Fikir Birliği alt boyutu ve HEXACO Kişilik Envanteri öz bildirim formuyla kendini, eşlerden diğeri ise HEXACO Kişilik Envanteri gözlemci formuyla eşini değerlendirmiştir. Sonuçlara göre HEXACO Kişilik Envanteri'nin gözlemci formunun 0,74-0,81 arasında iç tutarlılık güvenirlik katsayıları ve öz bildirim formuyla da 0,56 ile 0,71 arasında korelasyon gösterdiği hesaplanmıştır. HEXACO kişilik modeli açısından bakıldığında, bireylerin kendilerini değerlendirmesi ile eşlerinin değerlendirmeleri arasında sadece Deneyime Açıklık faktöründe farklılık görülmüş, diğer faktörlerde farklılık tespit edilememiştir. Fikir birliği düşük ve yüksek olan gruplar arasında ise Sorumluluk ve Deneyime Açıklık faktörleri açısından farklılık görülmüştür. Elde edilen sonuçlar öz bildirim-gözlemci formu farklılıkları, kişilik özellikleri, eş uyumu ve fikir birliği çerçevesinde tartışılmıştır.
\end{abstract}

Anahtar Kelimeler: Kişilik, HEXACO Kişilik Modeli, Evlilik Uyumu, Fikir Birliği

\section{Comparison of the Personality Profiles of Married Couples-II: using HEXACO Personality Model}

\begin{abstract}
This study aimed to examine the relationship between personality traits and marital adjustment in the framework of dyadic consensus. In this direction, the aim of the study was, a) to use and to test the observer form of the HEXACO Personality Inventory, b) to examine the HEXACO personality model in terms of marital adjustment, c) to examine the role of dyadic consensus of couples in marital adjustment. The participants of the study were 296 women and 253 men, a total of 549 people with their spouses a total of 1098 people who were married for a year and more. One of the spouse assessed oneself with the Dyadic Consensus subscale of the Dyadic Adjustment Scale and the HEXACO Personality Inventory self report form, the other spouse assessed his/her couple with the HEXACO Personality Inventory observer report form. The results showed that the internal consistence reliability coefficient of the HEXACO Personality Inventory observer report form was between 0.74 and 0.81 and its correlation coefficient with the self-report form was between 0.56 and 0.71 . According to HEXACO personality model, the difference between individuals' assessments of themselves and their spouses was only in the Openness to Experiences factor, no differences were detected in the other factors. Though, there were differences between low and high dyadic consensus groups in the factors of Conscientiousness and Openness to Experience factors. The results were discussed in terms of observed and selfreport form differences, personality traits, couple adjustment and dyadic consensus.
\end{abstract}

Key Words: Personality, HEXACO Personality Model, Marital Adjustment, Dyadic Consensus

\footnotetext{
${ }^{1}$ Doç. Dr., FSM Vakıf Üniversitesi, Edebiyat Fakültesi, Psikoloji Bölümü, İstanbul

${ }^{2}$ Psk., İstanbul Türkiye

Address of correspondence / Yazışma adresi: Doç. Dr. Arkun Tatar, FSM Vakıf Üniversitesi, Edebiyat Fakültesi, Psikoloji Bölümü, İstanbul Türkiye e-posta: arkuntatar@yahoo.com

Date of Received/Geliş Tarihi: 09.10.2019, Date of Revision/Düzeltme Tarihi: 16.02.2020, Date of Acceptance/Kabul Tarihi: 20.03.2020

Citing/ Referans Gösterimi: Tatar, A., Saltukoğlu, G., Özdemir, H. (2020). Evli Çiftlerin Kişilik Profillerinin Karşılaştırılması-II: HEXACO Kişilik Modeli. Kıbrıs Türk Psikiyatri ve Psikoloji Dergisi, 2(1): 5-13. doi:10.35365/ctjpp.20.2.1
} 


\section{Giriş}

Bireylerin kişilik özellikleri, evlilik uyumunun temel yordayıcılarından biri olarak değerlendirilmektedir (Bouchard, Lussier ve Sabourin, 1999; Donnellan, Conger ve Bryant, 2004; Ghasemi, Askarizadeh ve Mosavi-nasab, 2020; Kelly ve Conley, 1987). Evlilik uyumunun, kişilik özellikleri ile ilişkilendirilmesi ise yaygin olarak beş faktörlü modelle sunulan çözümlemelere dayalı olarak gerçekleştirilmektedir (Bouchard ve ark., 1999; Chen ve ark., 2007; Malouff, Thorsteinsson, Schutte, Bhullar ve Rooke, 2010; Watson, Hubbard ve Wiese, 2000; Wollny, Jacobs ve Pabel, 2020). Bununla birlikte, evli çiftler ile yürütülen çalışmaların birçoğunda beş kişilik faktörü arasından duygusal denge ve uyumluluk faktörleri üzerinde durulduğu görülmektedir (Casale, Fioravanti, Baldi, Flett ve Hewitt, 2019; Mousavi, 2017).

Duygusal denge faktörü, değişken duygusal durum, dürtüsellik, endişeye yatkınlık, öz-güven eksikliği, öfke ve düşmanlık boyutlarını kapsamaktadır (McCrae ve Costa, 1987; 1997). Bu faktörün endişeli, kaygıll, kötümser, huzursuz, hassas, alıngan, kırılgan, kıskanç, duygusal tutarsız olarak tanımlanan ucunda yer alan bireylerin, ruh hallerini yansıtır biçimde tutarsız davranışlar sergiledikleri, bu duruma bağlı olarak da özellikle kadınların uyum problemi yaşadıkları ifade edilmektedir (Bouchard ve ark., 1999; Buss, 1991; Chen ve ark., 2007; Kelly ve Conley, 1987; Mousavi, 2017; Nemechek ve Olson, 1996; Sohrabi ve Narimani, 2018). Buna karşın, uyumluluk faktörünün evlilik uyumu ile pozitif yönde ilişkili olduğu rapor edilmektedir (Bouchard ve ark., 1999; Gattis, Berns, Simpson ve Christensen, 2004; Nemechek ve Olson, 1996). Uyumluluk faktörü, hoşgörü, sakinlik, uzlaşma, geçimlilik, uysallık, yumuşak başlılık, alçak gönüllülük, elseverlik, doğruluk ve güven boyutlarıla değerlendirilmektedir (McCrae ve Costa, 1987; 1997). Bu faktörün çatışmadan kaçınan, geçimli, işbirliğine yatkın, insanlara güvenen merhametli ve özgeci olarak tanımlanan ucunda yer alan çiftlerin daha az çatışma yaşadıkları ve (özellikle erkek grubun) uyum düzeylerinin daha yüksek olduğu ifade edilmektedir (Bouchard ve ark., 1999; Chen ve ark., 2007; Mousavi, 2017). Ayrıca Dışadönüklük, Sorumluluk ve Deneyime Açıklık faktörleri ile evlilik uyumu arasında pozitif bir ilişki bulunduğunu rapor eden çalışmalar da bulunmaktadır (Bouchard ve ark., 1999; Buss, 1991; Donnellan ve ark., 2004; Krishnaswamy ve Mantri, 1997; Mousavi, 2017).

Beş faktör modeli 1980 ve 1990'larda kişiliği açıklamak için en uygun model olarak kabul edilse de (Gorbaniuk, Budzinska, Owczarek, Bozek ve Juros, 2013) daha yakın tarihlerde ortaya konulan altı faktörlü HEXACO modelinin (Ashton ve Lee, 2002; 2007; Ashton, Lee ve Goldberg, 2004) göre daha kapsamlı olması nedeniyle daha güçlü olduğu belirtilmektedir (Ashton ve ark., 2006; Ashton ve ark., 2004). HEXACO kavramı, modelde yer alan faktörlerin (Alçak Gönüllülük-Dürüstlük ((H)umility-Honesty), Duygusallık ((E)motionality), Dişadönüklük (E(X)traversion), Uyumluluk ((A)greeableness), Sorumluluk (Conscientiousness) ve Deneyime Açıklı ((O)penness to Experience)) İngilizce isimlerinin ilk harflerinden oluşmakta ve faktör sayısına işaret etmektedir (Ashton ve Lee, 2009a; Lee ve Ashton, 2004; 2018).
HEXACO modelindeki Alçak Gönüllülük-Dürüstlük faktörü Beş Faktör Mode l'inden yer almayan en önemli farklılık olarak belirtilmektedir (Ashton ve Lee, 2005; 2008a; 2008b). Faktör, İçtenlik, Doğruluk, Hırstan Kaçınma ve Tevazu alt boyutlarından oluşmaktadır (Ashton ve Lee, 2007). Alçak gönüllülük algısının bir ilişkideki olumsuz deneyimlere duyarlı olduğu, bireyin, herhangi bir durumda incinmesine bağlı olarak yakın çevresindeki diğer insanların tevazusu hakkında yaptığ değerlendirmelerin değişim gösterebileceği ifade edilmektedir (Farrell ve ark., 2015). Ayrıca, bireylerin alçak gönüllülük düzeylerinin belirlenmesi amaciyla özbildirime dayalı olarak gerçekleştirilen ölçümlerden elde edilen sonuçların yanıltıcı olabileceği belirtilmektedir. Gerçekten alçak gönüllü olan kişilerin, soruları mütevazı bir tutumla cevaplandırdıkları, alçak gönüllü olmayan kişilerin ise kendilerini olduklarından daha alçak gönüllü göstermeye çalıştıkları, bu nedenle de yapının ölçüm güçlüğü içerdiği ifade edilmektedir (Davis ve ark., 2013). Pozitif psikolojiye yönelik ilginin artmasıyla birlikte alçak gönüllülük ve tevazu gibi olguların ölçülmesine yönelik ilgi de artış göstermiştir (Davis ve ark., 2011). Alçak gönüllülüğün kavramsallaştırıldığı çalışmalarda, olgunun affetme ve özür dileme gibi uzlaşmacı davranışlarla ilişkili olduğu rapor edilmiştir (Davis ve ark., 2011; Van Tongeren, Davis ve Hook, 2014). Bu özelliğe sahip bireylerin, yaşanan çatışmalarda kendi rollerini daha doğru bir şekilde değerlendirdikleri, bu doğrultuda da partnerlerine karşı daha olumlu tutumlar sergiledikleri ileri sürülmektedir (Farrell ve ark., 2015). Ayrıca alçak gönüllülüğün, romantik bir ilişkiyi başlatma, sürdürme ve onarmada etkili olduğu ortaya konulmuştur (Van Tongeren ve ark., 2014).

Duygusallık faktörü, Korkaklık, Kaygı, Bağımlılık ve Duyarlılık alt boyutlarından oluşmaktadır (Lee ve Ashton, 2018). Bu faktör, Beş Faktör Modeli'nde yer alan Duygusal Denge faktörüne karşıllk gelmekte, ancak ruh halinde görülen süreğen tutarsız değişimi ve düşmanlık, öfke, kızgınlık gibi duyguları içermemektedir (Ashton, Lee ve de Vries, 2014; Ashton ve ark., 2004). Dışadönüklük faktörü, Sosyal Dışavurumculuk / Sosyal Öz-Sayg1, Sosyal Girişkenlik, Sosyallik ve Canlılık alt boyutlarıyla değerlendirilmektedir (Lee ve Ashton, 2018). Faktörün, bir ucuyla tanımlı olmak koşuluyla dışa dönüklük, girişkenlik, konuşkanlık, sosyallik, neşelilik, aktiflik, yalnızlık, sessizlik gibi özellikleri taşıdığı, Beş Faktör Kişilik Modeli'ndeki cesurluk, dayanıklılık, kendine güven gibi özellikleri ise kapsamadığ 1 ifade edilmektedir (Ashton ve Lee, 2007; 2009; Lee ve Ashton, 2004). Uyumluluk faktörü, Bağışlayıcılık, Yumuşaklık, Esneklik ve Sabır alt boyutlarından oluşmaktadır ve sabırlılık, uyumluluk, hoşgörülülük, 1lımlılık, kızgınlık, aksilik, hırçınlık, huysuzluk, geçimsizlik gibi özelliklerle tanımlanmaktadır. Faktörün duygusallığı içermediği belirtilmektedir (Ashton ve Lee, 2007; Ashton ve ark., 2014; Lee ve Ashton, 2018). Sorumluluk faktörü, Düzenlilik, Çalışkanlık, Mükemmeliyetçilik, Tedbirlilik alt boyutlarından oluşmaktadır ve düzenlilik, çalışkanlık, planlılık, dikkatlilik, titizlik, dağınıklık, unutkanlık, dalgınlık, sorumsuzluk gibi özelliklerle tanımlanmaktadır. Faktörün öz-disipline ve başarı odaklılığa işaret ettiği belirtilmiştir (Ashton ve ark., 2014; Lee ve Ashton, 2004; 2018). Modelde sonuncu faktör olarak yer alan Deneyime Açıklık faktörü, Estetik Beğeni / Estetik Değerleme, Meraklılık, Yaratıcılık ve Geleneksel Olmama alt boyutlarından oluşmaktadır. Faktör, yaratıcılığa, geleneksel olmamaya, aydınlığa, 
yaratıcı yenilikçiliğe işaret etmekte ve sanata, açık fikirliliğe, hayal gücüne, özgünlüğe vurgu yapmaktadır (Lee ve Ashton, 2004; 2018).

Evlilik uyumu ve altı faktörlü kişilik modeli çerçevesinde kişilik özellikleri ile ilişkisi HEXACO kişilik modelinde yer alan faktörlerin içeriklerinin Beş Faktör Modeli'nde yer alan faktörlerden farklı olması nedeniyle ayrılmaktadır. Ayrıca sadece Beş Faktör Modeli'nde yer almayan Alçak Gönüllü̈lük faktörünün, içerdiği özellikler nedeniyle evlilik uyumu açısından önemli olabileceği dikkate alındığında, bu çalışmada evlilik uyumunun altı faktörlü modele dayalı olarak değerlendirilmesi önemli olmaktadır. $\mathrm{Bu}$ bilgiler doğrultusunda bu çalışmada, HEXACO Kişilik Envanteri'nin altı faktörlü yapısal özellikleri üzerinden eş uyumunun incelenmesi amaçlanmıştır. Bu doğrultuda Türkçe HEXACO Kişilik Envanteri'nin faktör puanlarının önce cinsiyet grupları (kadın-erkek), daha sonra fikir birliği grupları (ortalama alt1-ortalama üstü) son olarak da çiftler (öz bildirimgözlemci formları) açısından karşılaştırılması planlanmıştır. Gözlemci ve öz bildirim ilişkisi bağlamında uyum geçerliği işlemi olarak yapılan karşılaştırmalarda, öz bildirim ve gözlemci formundan elden edilen puanlar arasındaki uyumun, kendini değerlendiren kişi ile gözlemcinin yakınlık derecesine bağlı olduğu belirtilmektedir (Ashton ve Lee, 2010; de Vries, Lee ve Ashton, 2006; 2008; Lee ve Ashton, 2017; McCrae ve Costa, 1987; Oh, Wang ve Mount, 2011). Bu doğrultuda, bu çalışmada evli ve birlikte yaşayan çiftler üzerinde bireylerin kişilik özelliklerine yönelik kendi öznel değerlendirmeleri ile o kişinin özelliklerine yönelik eşinin yaptığı değerlendirmeler arasındaki benzerlik ve farklılıklarının ilişkisel modelle ortaya konulması işlemleri yürütülmüş, elde edilen sonuçlar evlilik uyumu bağlamında değerlendirilmiştir.

\section{Yöntem}

\section{Katılımcılar}

Çalışmaya bir yıl ve daha uzun süre ile evli olan 549 çift, toplam 1098 kişi katılmıştır. Çalışmaya (dışlama kriteri olarak) evli olmayanlar, bir yıldan kısa süre ile evli olanlar ve evli olup ayrı yaşayanlar alınmamıştır. Çiftlerin öz bildirim uygulamasına 296 kadın $(\% 53,9)$ ve 253 erkek $(\% 46,1)$ katılmıştır. Çiftlerin, öz bildirim uygulamasına katılanlarının 20-65 yaşları arasıda (ortalama $=36,34 \pm 9,48$ yıl), eşlerinin ise 21-63 yaşları arasında (ortalama $=36,26 \pm 9,45$ yil) olduğu görülmüştür. Çiftlerin 1-39 yıl arasında (ortalama $=11,20$ $\pm 9,56$ yıl) süreyle evli oldukları ve ekonomik durumlarını 10'unun kötü $(\% 1,8), 319$ 'unun orta düzeyde $(\% 58,1)$ ve 214 'ünün iyi düzeyde $(\% 39,0)$ tanımladıkları (6 çift belirtmemiştir $(\% 1,1)$ ) tespit edilmiştir. Çiftlerin, öz bildirim uygulamasına katılanlarının 109'u ilk veya orta okul mezunu (\%19’9), 184'ü lise mezunu $(\% 33,5)$, 256's1 üniversite mezunu $(\% 46,6)$, eşlerinin ise 107'si ilk veya orta okul mezunu $(\% 19,5)$, 189'u lise mezunu $(\% 34,4)$ ve 253 'ü de üniversite mezunu $(\% 46,1)$ kişiler olduğu görülmüştür.

\section{Uygulama}

Çalışma, "gönüllü olur" formuyla yapılan açıklamayı her ikisi de kabul eden çiftlerle yürütülmüştür. Çiftlerden biri kendini değerlendirmek amaciyla HEXACO Kişilik Envanteri'nin öz bildirim formunu ve Çift Uyum Ölçeği'nin Fikir Birliği alt boyutunu, çiftlerden diğeri de eşini değerlendirmek amacıyla HEXACO Kişilik Envanteri’nin gözlemci formunu cevaplamıştır. Çiftlerden kimin öz bildirim formunu, kimin gözlemci formunu dolduracağına kendileri karar vermişlerdir. $\mathrm{Bu}$ şekilde çiftlerden birisi için HEXACO Kişilik Envanteri'nin öz bildirim ve gözlemci formlarından oluşan iki değerlendirme elde edilmiştir. Uygulama İstanbul ilinde yürütülmüş ve çiftlerin değerlendirmeleri birbirlerinden bağımsız olarak yapmaları istenmiştir. Çiftlerden her birinin formları doldurması yaklaşık yarım saat sürmüştür.

\section{Gereçler}

HEXACO Kişilik Envanteri'nin 100 maddeli uzun formu, üst düzey altı faktör ve bu faktörler altında yer alan 24 alt boyuttan oluşmaktadır (Ashton ve ark., 2014; Lee ve Ashton, 2006). Envanter'in Türkçe'ye çeviri işlemleri geliştiren yazarlar tarafindan yürütülmüş ve Türkçe kısa ve uzun formların psikometrik özellikleri de test edilmiştir (Tatar, 2018). Envanterin uzun ve kısa formları yanı sıra öz bildirim ve gözlemci formları da vardır (Ashton ve Lee, 2009b; Lee ve Ashton, 2004; 2006; 2018). Envanter, 1 = kesinlikle katılmıorum ve 5 $=$ kesinlikle katılıyorum arasında 5'li Likert tipi değerlendirilmektedir. Bu çalışmada envanterin Türkçe uzun öz bildirim ve gözlemci formu kullanılmıştır. Türkçe uzun form için faktörlerinin 0,72 ile 0,78 arasında değişen iç tutarlık katsayıları gösterdiği bildirilmiştir (Tatar, 2018).

Çift Uyum Ölçeği, Spanier (1976) tarafından geliştirilmiş, Türkçe çeviri işlemleri de Fişiloğlu ve Demir (2000) tarafindan yürütülmüştür. 32 Maddeli ölçek Fikir Birliği, Memnuniyet-doyum, Bağlllık ve Duygusal İfade olmak üzere dört alt boyutla değerlendirilmektedir. $\mathrm{Bu}$ çalışmada kullanılan Fikir Birliği alt boyutu 13 maddeden ve $0=$ her zaman anlaşamayız ile $5=$ her zaman anlaşırız arasında 6'lı Likert tipi değerlendirmeden oluşmaktadır. Yüksek puanın fikir birliğini gösterdiği bu alt boyutta iç tutarlılık güvenirlik katsayısı Türk örneklem grubu için 0,75 olarak belirtilmiştir.

\section{Verilerin Analizi}

Çalışmada, kullanılan ölçek ve envanterlerin Alfa iç tutarlık güvenirlik katsayılarının hesaplanması, ölçek toplam puanları arası karşılaştırmada Pearson korelasyon analizi, grupların HEXACO kişilik Envanteri faktör puanlarının karşılaştırılmasında, Çift Uyum Ölçeği, Fikir Birliği alt boyut toplam puanının ortak değişken olarak alındığı çok değişkenli kovaryans analizi (MANCOVA) ve çok değişkenli varyans analizi (MANOVA) yapılmıştır.

\section{Sonuçlar}

Çalışma verisinde tüm grup için önce öz bildirim ve gözlemci formlarının ayrı ayrı iç tutarlılık güvenirlik katsayıları hesaplanmıştır. Altı faktörün iç tutarlılık güvenirlik katsayıları öz bildirim uygulamasında 0,68 0,79, gözlemci formu uygulamasında da 0,74-0,81 arasında gerçekleşmiştir. Daha sonra Çift Uyum Ölçeği, Fikir Birliği alt boyut toplam puanı ile HEXACO Kişilik Envanteri'nin faktörleri arasında tüm grup ve cinsiyet grupları için ayrı ayrı korelasyon analizi yapılmıştır. Sonuçlara göre Fikir Birliği alt boyut toplam puan1, öz bildirim uygulaması ile tüm grupta $-0,01$ ile $-0,13$, kadın 
grubunda $-0,02$ ile $-0,13$, erkek grubunda $-0,05$ ile $-0,18$ arasında korelasyon katsayısı göstermiştir. HEXACO Kişilik Envanteri'nin faktörlerinin öz bildirim ve gözlemci formları arasında ise tüm grup için 0,56 ile
0,71 , kadın grubu için 0,53 ile 0,71 , erkek grubu için de 0,48 ile 0,71 arasında korelasyon katsayısı hesaplanmıştır (Tablo 1).

Tablo 1. HEXACO Kişilik Envanteri’nin gözlemci ve öz bildirim formları için içtutarlılık güvenirlik ve toplam puanları arası korelasyon katsayıları

\begin{tabular}{|c|c|c|c|c|c|c|}
\hline & $\mathbf{H}$ & $\mathbf{E}$ & $\mathbf{X}$ & $\mathbf{A}$ & $\mathbf{C}$ & $\mathbf{O}$ \\
\hline Öz Bildirim Uygulaması- $\alpha(n=549)$ & 0,79 & 0,68 & 0,73 & 0,70 & 0,72 & 0,75 \\
\hline Gözlemci Formu Uygulaması- $\alpha(n=549)$ & 0,81 & 0,75 & 0,74 & 0,76 & 0,77 & 0,76 \\
\hline \multicolumn{7}{|l|}{ Öz Bildirim-Gözlemci Formları Arası... } \\
\hline Tüm Grup-r (n=549) & $0,71 * * *$ & $0,58 * * *$ & $0,56^{* * *}$ & $0,60 * * *$ & $0,59 * * *$ & $0,61 * * *$ \\
\hline Kadın-r $(n=296)$ & $0,71 * * *$ & $0,54 * * *$ & $0,53 * * *$ & $0,62 * * *$ & $0,58 * * *$ & $0,61 * * *$ \\
\hline Erkek-r $(n=253)$ & $0,71 * * *$ & $0,48 * * *$ & $0,61 * * *$ & $0,56 * * *$ & $0,60 * * *$ & $0,60 * * *$ \\
\hline \multicolumn{7}{|l|}{ Fikir Birliği Alt Boyut Toplam Puanı ile... } \\
\hline Tüm Grup-r $(\mathrm{n}=549)$ & $-0,03$ & $-0,01$ & $-0,09 *$ & $-0,05$ & $-0,13^{* *}$ & $-0,12 * *$ \\
\hline Kadın-r $(n=296)$ & $-0,02$ & $-0,02$ & $-0,11$ & $-0,07$ & $-0,13^{*}$ & $-0,08$ \\
\hline Erkek-r $(n=253)$ & $-0,07$ & $-0,06$ & $-0,05$ & $-0,06$ & $-0,14 *$ & $-0,18 * *$ \\
\hline
\end{tabular}

$* \mathrm{p}<0,05 ; * * \mathrm{p}<0,01 ; * * * \mathrm{p}<0,001$

Çiftlerden elde edilen veriler farklı şekillerde karşılaştırılarak sunulmuştur. Bunlardan ilki kadın ve erkeklerin kendilerini değerlendirmeleri arasındaki benzerlik ve farklılıkların karşılaştırmasıdır. Kadın ve erkek gruplarının fikir birliği puanının ortak değişken olarak alındığı MANCOVA sonucuna göre altı faktör toplam puanları için yapılan analizde cinsiyet grupları için ana etki istatistiksel olarak anlamlıdır (Wilk's $\left.\lambda=0,814, \mathrm{~F}(6,541)=20,651 ; \mathrm{p}<0,001 ; \eta^{2}=0,186\right)$. Faktörler tek tek ele alındığında ise Dürüstlük-Alçak Gönüllülük $\left(\mathrm{F}(1,546)=7,166 ; \quad \mathrm{p}<0,01 ; \quad \eta^{2}=0,013\right), \quad$ Duygusall1k
$\left(\mathrm{F}(1,546)=114,609 ; \mathrm{p}<0,001 ; \eta^{2}=0,173\right)$ ve Geçimlilik $\left(\mathrm{F}(1,546)=12,476 ; \quad \mathrm{p}<0,001 ; \quad \eta^{2}=0,022\right) \quad$ faktörlerinde kadın ve erkeğin kendilerini değerlendirmelerine ilişkin puan ortalamaları arasında istatistiksel düzeyde anlamlı farklı1ık bulunmuştur. $\mathrm{Bu}$ faktörlerin üçünde de erkeklerin toplam puan ortalaması kadınların toplam puan ortalamasından düşüktür. Dışadönüklük, Sorumluluk ve Deneyime Açıklık faktörleri için ise kadın ve erkeklerin kendilerini değerlendirmelerine ilişkin ortalamalar arasında istatistiksel düzeyde anlamlı farklılık görülmemiştir (Bkz. Tablo 2, Şekil 1).

Tablo 2. Farklı gruplarda MANCOVA ve MANOVA ile kişilik faktörlerine ilişkin toplam puanlarının karşılaştırma sonuçları

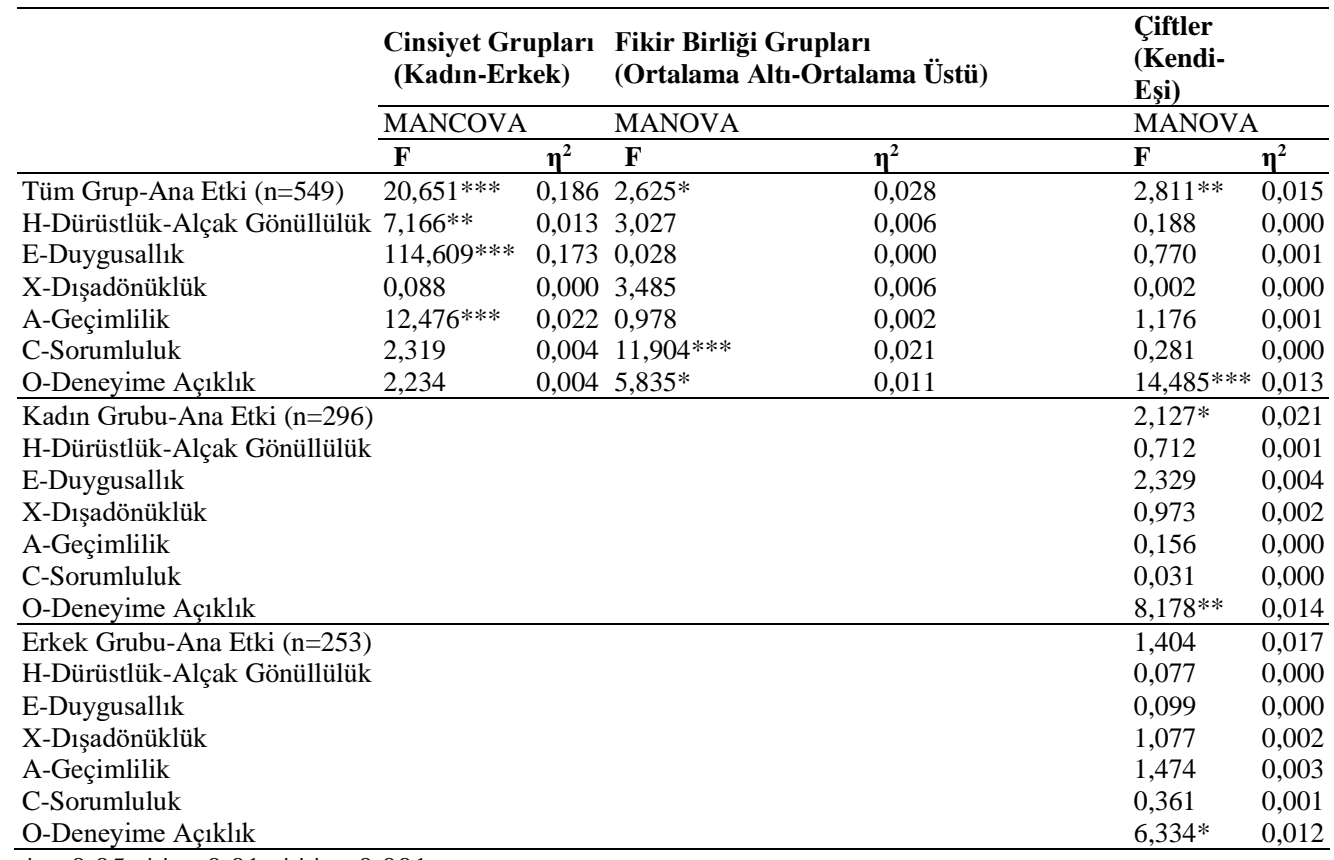

$* \mathrm{p}<0,05 ; * * \mathrm{p}<0,01 ; * * * \mathrm{p}<0,001$ 


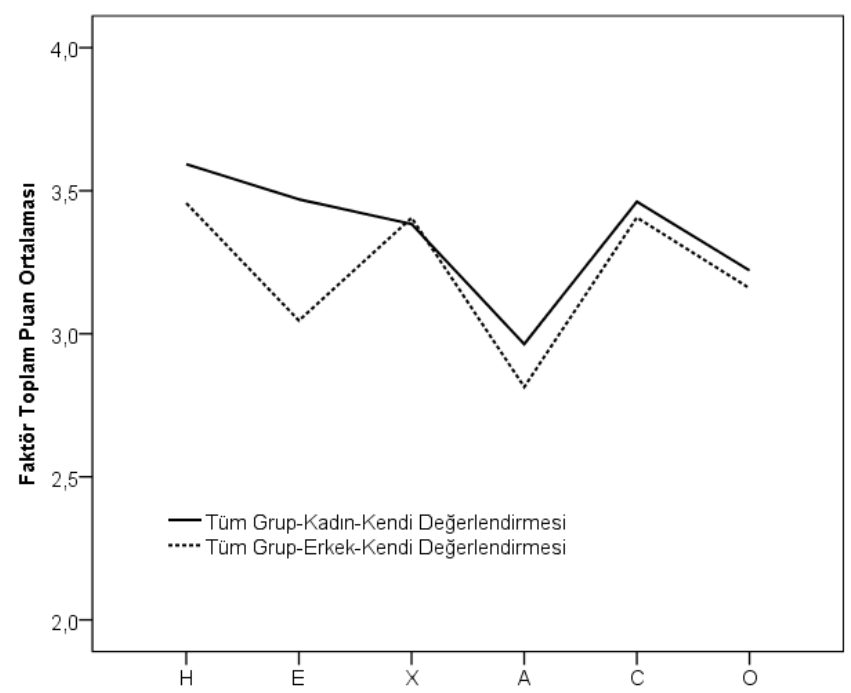

Şekil 1. Tüm grupta kadın ve erkeklerin kendi kişilik değerlendirmelerinin karşılaştırması

Katılımcıların Çift Uyum Ölçeği, Fikir Birliği alt boyut toplam puan1 ortalamas1 (ort. $=26,43, \mathrm{~s}=9,481$ ) kullanılarak ortalamanın altında ve üstünde yer alan iki grup oluşturulmuştur. Bu iki grubun HEXACO Kişilik Envanteri'nin öz bildirim değerlendirmelerine ilişkin altı faktör toplam puanları açısından yapılan MANOVA sonucuna göre ana etki istatistiksel olarak anlamlıdır (Wilk's $\left.\lambda=0,972, \quad F(6,542)=2,625 ; \mathrm{p}<0,05 ; \eta^{2}=0,028\right)$. Faktörler tek tek ele alındığında ise Sorumluluk $\left(F(1,547)=11,904 ; p<0,001 ; \eta^{2}=0,021\right)$ ve Deneyime Açıklık $\left(F(1,547)=5,835 ; p<0,05 ; \eta^{2}=0,011\right)$ faktörüne

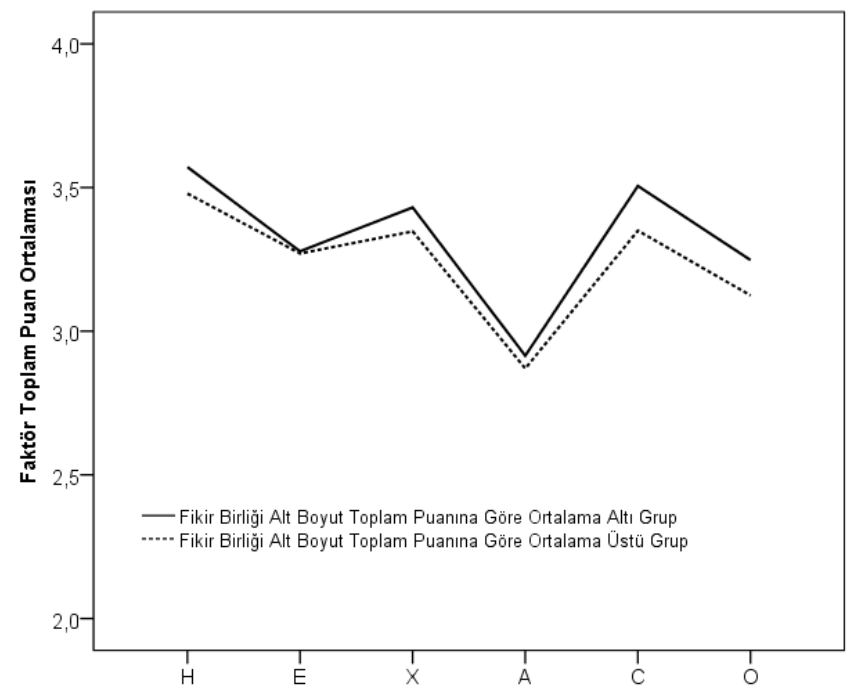

Şekil 2. Tüm grupta, Fikir Birliği alt boyut puan ortalamasının altında ve üstünde olanların kişilik değerlendirmelerinin karşılaştırması

Sonraki karşılaştırmada tüm katılımcı çiftlerde kişilerin kendilerini değerlendirmeleri ile eşlerinin değerlendirmelerine ilişkin altı faktör toplam puanları açısından yapılan MANOVA sonucuna göre ana etki istatistiksel olarak anlamlıdır (Wilk's $\lambda=0,985$, $\left.\mathrm{F}(6,1091)=2,811 ; \mathrm{p}<0,01 ; \eta^{2}=0,015\right)$. Faktörler tek tek ele alındığında ise sadece Deneyime Açıklık $\left(F(1,1096)=14,485 ; p<0,001 ; \eta^{2}=0,013\right)$ faktörüne ilişkin toplam puan ortalamaları arasında istatistiksel düzeyde anlamlı farklılık görülmüştür ve kişilerin kendilerini değerlendirmeleri eşlerinin değerlendirmelerinden daha ilişkin toplam puan ortalamaları arasında istatistiksel düzeyde anlamlı farklılık görülmüştür. Fikir Birliği alt boyut toplam puan1, ortalamanın altında kalan grubun hem Sorumluluk hem de Deneyime Açılık faktör toplam puan ortalaması diğer gruptan daha yüksektir. DürüstlükAlçak Gönüllülük, Duygusallık, Dişadönüklük ve Geçimlilik faktörleri için ise fikir birliği ortalamanın altında ve üstünde olan gruplar arasında istatistiksel düzeyde anlamlı farklılık tespit edilememiştir (Bkz. Tablo 2, Şekil 2). yüksektir. Dürüstlük-Alçak Gönüllülük, Duygusallık, Dışadönüklük, Geçimlilik ve Sorumluluk faktörleri için ise kişilerin kendilerini değerlendirmeleri ile eşlerinin değerlendirmelerine ilişkin ortalamalar arasında istatistiksel düzeyde anlamlı farklılık tespit edilememiştir (Bkz. Tablo 2).

Öz bildirim değerlendirmesi yapan katılımcılar, kadın ve erkek olarak ayrı ele alındıklarında, kadınların kendilerini değerlendirmeleri ile eşlerinin değerlendirmelerine ilişkin altı faktör toplam puanları açısından yapılan MANOVA 
sonucuna göre ana etki istatistiksel olarak anlamlıdır (Wilk's $\lambda=0,979, \quad F(6,585)=2,127 ; p<0,05 ; \eta^{2}=0,021$ ). Faktörler tek tek ele alındığında ise tüm grup için olduğu gibi sadece Deneyime Açılık $(\mathrm{F}(1,590)=8,178$; $\mathrm{p}<0,01$; $\left.\eta^{2}=0,014\right)$ faktörüne ilişkin toplam puan ortalamaları arasında istatistiksel düzeyde anlamlı farklılık görülmüştür ve kadınların kendilerini değerlendirmeleri eşlerinin değerlendirmelerinden daha yüksek bulunmuştur. Dürüstlük-Alçak Gönüllülük, Duygusallık, Dışadönüklük, Geçimlilik ve Sorumluluk faktörleri için ise kadınların kendilerini değerlendirmeleri ile eşlerinin değerlendirmelerine ilişkin ortalamalar arasında istatistiksel düzeyde anlamlı farklılık tespit edilememiştir (Bkz. Tablo 2, Şekil 3).

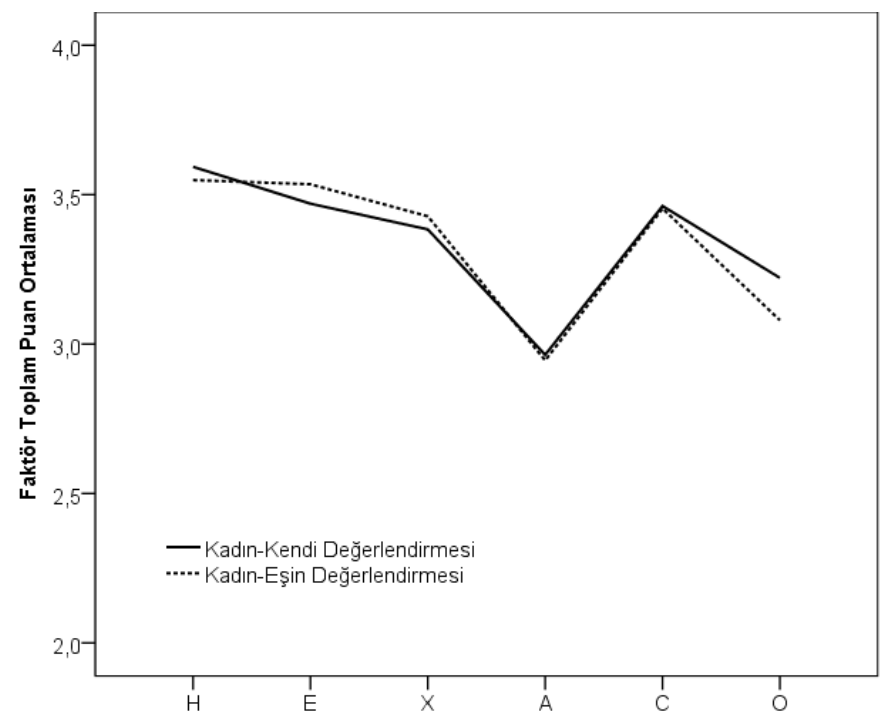

Şekil 3. Kadınların kendilerini değerlendirmesi ile eşlerinin kadınları değerlendirmesi arası karşılaştırma

Öz bildirim değerlendirmesi yapan katılımcılar içerisinde erkeklerin kendilerini değerlendirmeleri ile eşlerinin değerlendirmelerine ilişkin altı faktör toplam puanları açısından yapılan MANOVA sonucuna göre ise analizinde ana etki istatistiksel olarak anlaml değildir (Wilk's $\lambda=0,983, \mathrm{~F}(6,499)=1,404 ; \mathrm{p}>0,05 ; \eta^{2}=0,017$ ). Faktörler tek tek ele alındığında ise tüm grup ve kadın grubu için olduğu gibi sadece Deneyime Açılklk $\left(\mathrm{F}(1,504)=6,334 ; \mathrm{p}<0,05 ; \eta^{2}=0,012\right)$ faktörüne ilişkin toplam puan ortalamaları arasında istatistiksel düzeyde anlamlı farkl1lık görülmüştür ve erkeklerin kendilerini değerlendirmeleri, eşlerinin değerlendirmelerinden daha yüksek bulunmuştur. Dürüstlük-Alçak Gönüllülük, Duygusallık, Dişadönüklük, Geçimlilik ve Sorumluluk faktörleri için ise erkeklerin kendilerini değerlendirmeleri ile eşlerinin değerlendirmelerine ilişkin ortalamalar arasında istatistiksel düzeyde anlamlı farkl1lık tespit edilememişstir (Bkz. Tablo 2, Şekil 4).

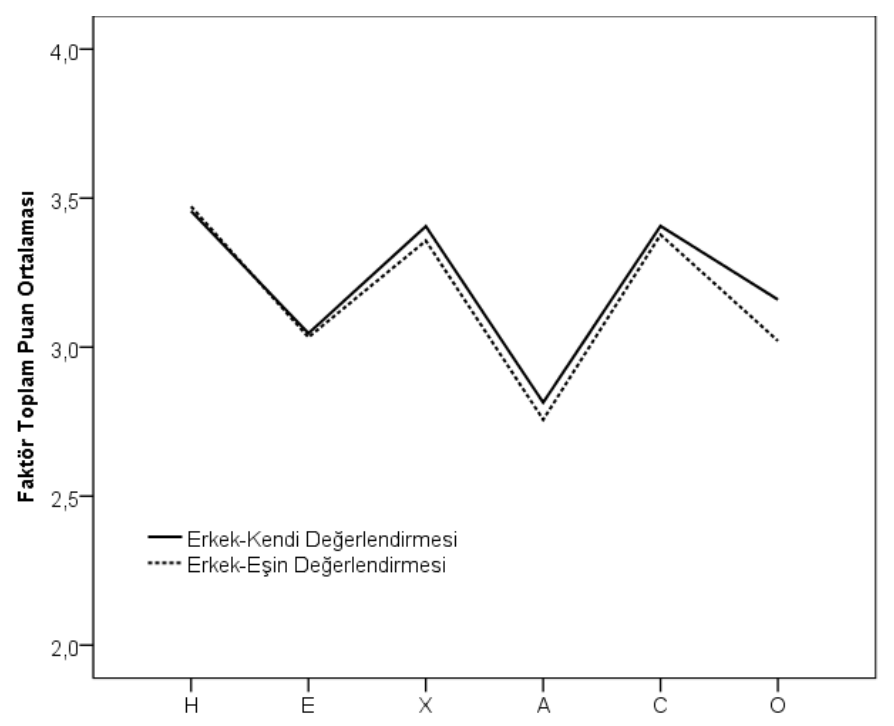

Şekil 4. Erkeklerin kendilerini değerlendirmesi ile eşlerinin erkekleri değerlendirmesi arası karşılaştırma 


\section{Tartışma}

Evlilik uyumu ve fikir birliği, sosyal ve psikolojik bir çok değişkenden etkilenmektedir. Ayrıca önceki çalışmalarda, evlilik uyumu, evlilik doyumu, mutluluk gibi olgusal yapılar biri birinin yerine kullanılırken konuyla ilgili görece yakın tarihli çalışmalarda bu olgular artık ayrı ayrı ele alınmaktadır (Fişiloğlu ve Demir, 2000). Çiftler arasıdaki uyum ise evliliğin sürdürülmesinde kritik rol oynamaktadır (Jessee ve ark., 2010). Kişilik özellikleri de evlilik uyumunun belirleyicilerinden biri olarak ele alınmaktadır (Donnellan ve ark., 2004; Tatar, Özdemir ve Çamkerten, 2019). Bu doğrultuda yürütülen çalışmalarda ise çoğunlukla Beş Faktör Kişilik Modeli’nin kullanıldığ görülmektedir (Malouff ve ark., 2010). Bu çalışmada yukarıda belirtilenler doğrultusunda evlilik uyumuna kişilik özellikleri üzerinden bakmak ve farklı bir yaklaşım olarak da HEXACO kişilik modelinin kullanılması düşünülmüştür. $\mathrm{Bu}$ doğrultuda hem HEXACO Kişilik Envanteri'nin öz bildirim formu yanında gözlemci formunun kullanılması ve test edilmesi, hem evlilik uyumu açısından beş faktör modeli yerine altı faktör kişilik modelinin incelenmesi, hem de evlilik uyumunda eşler arası fikir birliğinin rolünün incelenmesi düşünülmüştür.

Öz bildirim ve gözlemci formundan elden edilen puanlar aras1 uyumun, gözlemcinin kendini değerlendiren kişiye yakınlık derecesine bağlı olduğu daha önce belirtilmiştir (Ashton ve Lee, 2010; de Vries ve ark., 2006; 2008; Lee ve Ashton, 2017; McCrae ve Costa, 1987; Oh ve ark., 2011). Bu çalışmada da HEXACO Kişilik Envanteri'nin faktörlerinin öz bildirim ve gözlemci formları arasında Duygusallık ve Geçimlilik faktörlerinde kadınlar ve erkeler arasında farklılık görülürken, öz bildirim ve eş değerlendirmesi arasında tüm grupta, kadınlarda, erkeklerde ve Fikir Birliği puanı ortalamanın altında olan grup ile üstünde olan grup arasında farklılık görülmemiştir. Kişilik özellikleri olarak bu iki faktör, evlilik uyumu ile yüksek düzeyde ilişkili bulunmaktadır (Bouchard ve ark., 1999). Bu çalışmada da kadınların, bu iki faktör toplam puanlarının erkeklerden yüksek olarak belirlenmiş olmasına karşın fikir birliği düzeyi açısından farkl11ı görülmemiş olması bu faktörlerin evlilik uyumuna katkılarını göstermektedir. Buna karşın Fikir Birliği puanı ortalamanın altında olan grup ile üstünde olan grup arasında sadece Sorumluluk ve Deneyime Açıklık faktörleri açısından farklılık görülmüştür. Ancak fikir birliği düşük olan grubun, her iki faktör toplam puan ortalaması diğer gruptan daha yüksektir. Diğer bir ifadeyle eşi ile daha düşük düzeyde fikir birliği bildiren grubun sorumluluk ve deneyime açıklık özellikleri eşi ile fikir birliği yüksek olan gruba göre daha yüksektir. Sorumluluk faktörü açısından bu sonuç, eşler arasında fikir birliği düşük düzeyde olduğu durumda sorumluluğun üstlenildiğini (ya da sorumluluk özellikleri gösterildiğini) ortaya koymaktadır. Diğer yandan kadın ve erkek gruplarının karşılaştırmasında Dışadönüklük, Sorumluluk ve Deneyime Açıklık faktörleri açısından, Fikir Birliği puanı ortalamanın altında olan ile üstünde olan grubun karşılaştırmasında ise Dürüstlük-Alçak Gönüllülük, Duygusallık, Dışadönüklük ve Geçimlilik faktörleri açısından farklılık görülmemiştir. Bu sonuçlara göre Dışadönüklük faktörünün hem kadın-erkek grupları açısından hem de fikir birliği düşük-yüksek gruplar açısından farklılık göstermediği anlaşılmaktadır. tüm grup için 0,56 ile 0,71 arasında korelasyon katsayıları elde edilmiştir. Kadın ve erkek grupları ayrı ayrı ele alındığında da küçük farklarla benzer katsayılar hesaplanmıştır. Ayrıca gözlemci formu uygulaması iç tutarlılık katsayıları da yine küçük farklarla öz bildirim formu uygulamasına benzer düzeylerde hesaplanmıştır. $\mathrm{Bu}$ sonuçlar HEXACO Kişilik Envanteri'nin Türkçe gözlemci formunun, öz bildirim formuna benzer şekilde çalıştığını göstermektedir.

Bu çalışmada karşılaştırılan gruplar açısından, Beş Faktör Modeli'nde yer almayan HEXACO Kişilik Modeli'nin Dürüstlük-Alçak Gönüllülük faktörüne ilişkin elde edilecek sonuçlar önemli rol oynamaktadır. Çünkü iki kişilik modelinin karşılaştırılması ya da birbirlerinin yerine kullanılmaları durumunda farklılığı büyük ölçüde bu faktör ortaya koymaktadır. Ayrıca Dürüstlük-Alçak Gönüllülük faktörünün, içerdiği özellikler nedeniyle de evlilik uyumunda önemli olabileceği düşünülmüştür. Faktörün işaret ettiği yapının, romantik bir ilişkiyi başlatma, sürdürme ve affetme, özür dileme gibi uzlaşmacı davranışlarla ilişskili olduğu bildirilmektedir (Davis ve ark., 2011; van Tongerenve ark., 2014). Tüm grupta öz bildirim uygulaması sonuçlarında bu faktör açısından kadın ve erkekler arasında, kadınların toplam puan ortalamaları daha yüksek olacak şekilde farklılık görülmüştür. Fikir Birliği puanı ortalamanın altında olan grup ile üstünde olan grup arasında ise bu faktör açısından farkl1lık görülmemiştir. Diğer bir ifadeyle eşler arası fikir birliğinin düzeyi, eşlerin bu faktöre ilişkin değerlendirmeleri açısından farklılık yaratmamaktadır.

Öz bildirim ve gözlemci yani eş değerlendirmesi arası farklılıklar incelendiğinde ise sadece Deneyime Açıklık faktörü açısından hem tüm grupta, hem kadınlarda hem de erkeklerde farklılık belirlenmiştir. Her üç karşılaştırmada da kişilerin kendilerini eşlerinin bildirdiğinden daha yüksek düzeyde deneyime açık olarak bildirdikleri görülmektedir. Oysa bu çalışma deseni açısından öz bildirim ve gözlemci yani eş değerlendirmesi arası farklılık olmaması daha tercih edilir bir sonuç olarak görünmektedir. $\mathrm{Bu}$ doğrultuda Dürüstlük-Alçak Gönüllülük, Duygusallık, Dışadönüklük, Geçimlilik ve Sorumluluk faktörlerinde kişilerin kendi değerlendirmeleriyle eşlerinin değerlendirmesi arasında hem tüm grupta, hem sadece kadınlarda hem de sadece erkeklerde farklılık görülmemiştir. Deneyime Açıklı faktör içeriğinin, yaratıcı yenilikçiliği, hayal gücünü, açık fikirliliği, özgünlüğü yansıttığı (Lee ve Ashton, 2004; 2018) dikkate alındığında ise sosyal istenirliğin öne çıktığı ve bu nedenle kişilerin kendilerini değerlendirmelerinin eşlerinin değerlendirmesinden daha yüksek düzeyde ortalama gösterdiği düşünülebilir.

Özet olarak tekrarlandığında HEXACO Kişilik Envanteri'nin öz bildirim formu yanında kullanılan gözlemci formunun öz bildirim formuna benzer özellikler gösterdiği görülmüş̧ür. Bu iki değerlendirme arası uyum, kişiler birbirlerine ne kadar yakınlarsa o kadar yüksek olmakta, bu nedenle de çiftlerin değerlendirmeleri arası uyum değerleri daha yüksek beklenmektedir (Ashton ve Lee, 2010; de Vries ve ark., 2006; 2008; Lee ve Ashton, 2017; McCrae ve Costa, 1987; Oh ve ark., 2011). Bu doğrultuda, bu çalışmada, Deneyime Açıklık faktörü dışındaki diğer faktörler açısından bireylerin kendilerini değerlendirmesi ile eşlerinin değerlendirmeleri arasında 
farkl1l1k görülmemesi bir yönüyle ölçeğin geçerliliğine katk1 sağlarken, diğer yönüyle de HEXACO kişilik modelinde yer alan kişilik özellikleri açısından eşlerin birbirlerini algılama şekillerini yani uyumu yansıtmaktadır. Her ne kadar beş faktör modelinin kişilik araştırmaları içerisinde önde gelen model olduğu kabul edilse de (de Raad ve Mlacic 2017) önerilen modeller içerisinde hangisinin kişilik özelliklerini daha iyi yansıttı̆̆ noktasında bir fikir birliği bulunmamaktadır (Block, 1995; Saucier, Ostendorf ve Peabody, 2001). Bu yönüyle bu çalışmada elde edilen sonuçlar HEXACO kişilik modeline yönelik bir farklılık olarak görülmektedir. Fikir birliği bağlamında eş uyumu açısından sorumluluk ve deneyime açıklık faktör özelliklerine yönelik eşlerin değerlendirmeleri arasında farklılık gözlenmesi ise bu özelliklere yönelik eşler arası fikir birliğinin olmamasını yansıtmaktadır. Bu sonuç ise eş uyumunda, ele alınması gereken olgulardan biri olarak fikir birliğinin önemini göstermektedir.
$\mathrm{Bu}$ çalışmada eş uyumu bağlamında değerlendirilmek üzere kişilik özellikleri yanında sadece fikir birliğinin alınmış olması çalışmanın en önemli sınırlılığı olarak görünmektedir. Eş uyumunu belirleyen pek çok değişken vardır ve bunlar arası etkileşimde önemli olmaktadır (Chen ve ark., 2007; Fişiloğlu ve Demir, 2000; Jessee ve ark., 2010; Mousavi, 2017; Sohrabi ve Narimani, 2018). $\mathrm{Bu}$ nedenle eş uyumu kapsamında daha fazla sayıda değişkenin kişilik özellikleri ile birlikte iliş̧ilendirilmesine gerek duyulmaktadır. Ayrıca eşlerin ekonomik durumu, eğitim durumu, çalışma durumu, çocuk sayısı gibi eşler arası uyumu etkileyebilecek olası sosyo-demografik değişkenlerden bağımsız olarak yapılan tüm karşılaştırmaların ayrıntıdan yoksun sonuç üreteceği açıktır. Bu nedenle benzer çalışmaların ya tüm bu değişkenleri bütünüyle kapsayacak daha büyük katılımcı gruplarında ya da tüm bu değişkenlerin kontrol altına alındığı daha küçük ama özellikleri daha iyi tanımlı gruplarda tekrarlanması gerektiği anlaşılmaktadır.

\section{Kaynaklar}

Ashton, M. C., \& Lee, K. (2001). A theoretical basis for the major dimensions of personality. European Journal of Personality, 15(5), 327-353.

Ashton, M. C., \& Lee, K. (2002). Six independent factors of personality variation: a response to Saucier. European Journal of Personality, 16(1), 63-75.

Ashton, M. C., \& Lee, K. (2005). Honesty-humility, the Big Five, and the Five-Factor Model. Journal of Personality, 73(5), 1321-1354.

Ashton, M. C., \& Lee, K. (2007). Empirical, theoretical, and practical advantages of the HEXACO model of personality structure. Personality and Social Psychology Review, 11(2), 150166.

Ashton, M. C., \& Lee, K. (2008a). The HEXACO model of personality structure and the importance of the $\mathrm{H}$ factor. Social and Personality Psychology Compass, 2(5), 1952-1962.

Ashton, M. C., \& Lee, K. (2008b). The prediction of HonestyHumility-related criteria by the HEXACO and Five-Factor Models of personality. Journal of Research in Personality, 42(5), 1216-1228.

Ashton, M. C., \& Lee, K. (2009a). An investigation of personality types within the HEXACO personality framework. Journal of Individual Differences, 30(4), 181-187.

Ashton, M. C., \& Lee, K. (2009b). The HEXACO-60: a short measure of the major dimensions of personality. Journal of Personality Assessment, 91(4), 340-345.

Ashton, M. C., \& Lee, K. (2010). Trait and source factors in HEXACO-PI-R self- and observer reports. European Journal of Personality, 24(3), 278-289.

Ashton, M. C., Lee, K., \& de Vries, R. E. (2014). The HEXACO Honesty-Humility, Agreeableness, and Emotionality factors: a review of research and theory. Personality and Social Psychology Review, 18(2), 139-152.

Ashton, M. C., Lee, K., \& Goldberg, L. R. (2004). A hierarchical analysis of 1,710 English personality-descriptive adjectives. Journal of Personality and Social Psychology, 87(5), 707-721.

Ashton, M. C., Lee, K., de Vries, R. E., Perugini, M., Gnisci, A., \& Sergi, I. (2006). The HEXACO model of personality structure and indigenous lexical personality dimensions in Italian, Dutch, and English. Journal of Research in Personality, 40(6), 851-875.

Ashton, M. C., Lee, K., Marcus, B., \& de Vries, R. E. (2007). German lexical personality factors: relations with the HEXACO model. European Journal of Personality, 21(1), 23-43.
Ashton, M. C., Lee, K., Perugini, M., Szarota, P., de Vries, R. E., di Blas, L. ... de Raad, B. (2004). A six-factor structure of personality-descriptive adjectives: solutions from psycholexical studies in seven languages. Journal of Personality and Social Psychology, 86(2), 356-366.

Babarović, T., \& Šverko, I. (2013). The HEXACO personality domains in the Croatian sample. Društvena Istraživanja: Časopis Za Opća Društvena Pitanja, 22(3), 397-411.

Block, J. (1995). A contrarian view of the Five-Factor Approach to personality description. Psychological Bulletin, 117(2), 187215.

Bouchard, G., Lussier, Y., \& Sabourin, S. (1999). Personality and marital adjustment: utility of the Five-Factor Model of personality. Journal of Marriage and the Family, 61(3), 651660.

Buss, D. M. (1991). Conflict in married couples: personality predictors of anger and upset. Journal of Personality, 59(4), 663703.

Casale, S., Fioravanti, G., Baldi, V., Flett, G. L., \& Hewitt, P. L. (2019). Narcissism, perfectionistic self-presentation, and relationship satisfaction from a dyadic perspective:narcissism and relationship satisfaction. Self and Identity, 1-19.

Chen, Z., Tanaka, N., Uji, M., Hiramura, H., Shikai, N., Fujihara, S., \& Kitamura, T. (2007). The role of personalities in the marital adjustment of Japanese couples. Social Behavior and Personality, 35(4), 561-572.

Davis, D. E., Hook, J. N., Worthington Jr, E. L., van Tongeren, D. R., Gartner, A. L., Jennings, D. J., \& Emmons, R. A. (2011). Relational humility: conceptualizing and measuring humility as a personality judgment. Journal of Personality Assessment, 93(3), 225-234.

Davis, D. E., Worthington Jr, E. L., Hook, J. N., Emmons, R. A., Hill, P. C., Bollinger, R. A., \& van Tongeren, D. R. (2013). Humility and the development and repair of social bonds: two longitudinal studies. Self and Identity, 12(1), 58-77.

de Raad, B. \& Mlacic, B. (2017). The lexical foundation of the big five factor model. The Oxford Handbook of The Five Factor Model, 191-216.

de Vries, R. E., Lee, K., \& Ashton, M. C. (2008). The Dutch HEXACO Personality Inventory: psychometric properties, selfother agreement, and relations with psychopathy among low and high acquaintanceship dyads. Journal of Personality Assessment, 90(2), 142-151. 
Donnellan, M. B., Conger, R. D., \& Bryant, C. M. (2004). The Big Five and enduring marriages. Journal of Research in Personality, 38(5), 481-504.

Farrell, J. E., Hook, J. N., Ramos, M., Davis, D. E., van Tongeren, D. R., \& Ruiz, J. M. (2015). Humility and relationship outcomes in couples: the mediating role of commitment. Couple and Family Psychology: Research and Practice, 4(1), 14-26.

Fişiloğlu, H., \& Demir, A. (2000). Applicability of the Dyadic Adjustment Scale for measurement of marital quality with Turkish couples. European Journal of Psychological Assessment, 16(3), 214-218.

Gattis, K. S., Berns, S., Simpson, L. E., \& Christensen, A. (2004). Birds of a feather or strange birds? Ties among personality dimensions, similarity, and marital quality. Journal of Family Psychology, 18(4), 564-574.

Ghasemi, F., Askarizadeh, G., \& Mosavi-nasab, S. M. H. (2020). Relationship of personality traits, religious attitude and sexual satisfaction with tendency towards divorcee in paramedic females. Journal of Research on Religion and Health, 5(4), 2033.

Gorbaniuk, O., Budzinska, A., Owczarek, M., Bozek, E., \& Juros, K. (2013). The factor structure of Polish personalitydescriptive adjectives: an alternative psycho-lexical study. European Journal of Personality, 27(3), 304-318.

Jessee, A., Mangelsdorf, S., Brown, G., Schoppe-Sullivan, S., Shigeto, A., \& Wong, M. (2010). Parents' differential susceptibility to the effects of marital quality on sensitivity across the first year. Infant Behavior and Development, 33(4), 442-452.

Karney, B. R., \& Bradbury, T. N. (1995). The longitudinal course of marital quality and stability: a review of theory, methods, and research. Psychological Bulletin, 118(1), 3-34.

Kelly, E. L., \& Conley, J. J. (1987). Personality and compatibility: a prospective analysis of marital stability and marital satisfaction. Journal of Personality and Social Psychology, 52(1), 27-40.

Krishnaswamy, S., \& Mantri, P. R. (1997). Psychological correlates of marital adjustment among working women. International Journal of Sociology of the Family, 27(1), 127138 .

Lee, K., \& Ashton, M. C. (2004). Psychometric properties of the HEXACO Personality Inventory. Multivariate Behavioral Research, 39(2), 329-358.

Lee, K., \& Ashton, M. C. (2006). Further assessment of the HEXACO Personality Inventory: two new facet scales and an observer report form. Psychological Assessment, 18(2), 182-191.

Lee, K., \& Ashton, M. C. (2017). Acquaintanceship and self/observer agreement in personality judgment. Journal of Research in Personality, 70, 1-5.
Lee, K., \& Ashton, M. C. (2018). Psychometric properties of the HEXACO-100. Assessment, 25(5), 543-556

Malouff, J. M., Thorsteinsson, E. B., Schutte, N. S., Bhullar, N., \& Rooke, S. E. (2010). The Five-Factor model of personality and relationship satisfaction of intimate partners: a metaanalysis. Journal of Research in Personality, 44(1), 124-127.

McCrae, R. R., \& Costa Jr, P. T. (1997). Personality trait structure as a human universal. American Psychologist, 52(5), 509-516.

McCrae, R. R., \& Costa, P. T. (1987). Validation of the FiveFactor Model of personality across instruments and observers. Journal of Personality and Social Psychology, 52(1), 81-90.

Mousavi, R. (2017). Relationship between Big Five personality factors neuroticism, extraversion, agreeableness, openness, loyalty and marital adjustment. NeuroQuantology, 15(4), 63-68.

Nemechek, S., \& Olson, K. R. (1996). Personality and marital adjustment. Psychological Reports, 78(1), 26-26.

Oh, I. S., Wang, G., \& Mount, M. K. (2011). Validity of observer ratings of the Five-Factor Model of personality traits: a meta-analysis. Journal of Applied Psychology, 96(4), 762.

Saucier, G., Ostendorf, F., \& Peabody, D. (2001). The nonevaluative circumplex of personality adjectives. Journal of Personality, 69(4), 537-582.

Sohrabi, Z., \& Narimani, M. (2018). The roles of HEXACO personality dimensions and affects control in prediction of marital satisfaction. Journal of Fundamentals of Mental Health, 20(3), 219-227.

Spanier, G. B. (1976). Measuring dyadic adjustment: a new scale for assessing the quality ofmarriage and similar dyads. Journal of Marriage and the Family, 38, 15-28.

Tatar, A. (2018). Gözden Geçirilmiş Uzun ve Kısa Form Altı Faktörlü Kişilik Envanteri (HEXACO-PI-R) Türkçe formunun psikometrik özelliklerinin incelenmesi. Anadolu Psikiyatri Dergisi, 19(1), 5-13.

Tatar, A., Özdemir, H., \& Çamkerten, S. (2019). Evli Çiftlerin Kişilik Profillerinin Karşılaştırılması-I: 3600 Değerlendirme Tekniği. Kıbrıs Türk Psikiyatri ve Psikoloji Dergisi, 1(3), 180188.

van Tongeren, D. R., Davis, D. E., \& Hook, J. N. (2014). Social benefits of humility: initiating and maintaining romantic relationships. The Journal of Positive Psychology, 9(4), 313-321.

Watson, D., Hubbard, B., \& Wiese, D. (2000). General traits of personality and affectivity as predictors of satisfaction in intimate relationships: evidence from self-and partner-ratings. Journal of Personality, 68(3), 413-449.

Wollny, A., Jacobs, I., \& Pabel, L. (2020). Trait emotional intelligence and relationship satisfaction: the mediating role of dyadic coping. The Journal of Psychology, 154(1), 75-93. 